\title{
Lipid and Fatty Acid Composition of Mesocarp and Seed of Avocado Fruits Harvested at Northern Range in Japan
}

\author{
Fumio Takenaga*, Kaori Matsuyama, Shin Abe, Yasuyoshi Torii and Shingo Itoh \\ Department of Food Science and Technology, College of Bioresource Sciences, Nihon University (1866, Kameino, Fijisawa-shi, Kanagawa, \\ 252-8510, JAPAN)
}

\begin{abstract}
The lipid and fatty acid composition of the mesocarp and seed of avocado fruit grown and harvested in Japan, which is located at the northern range of the avacado, was investigated and compared to an imported avocado purchased commercially. The potential of the avocado mesocarp as an agricultural product in Japan was also explored. Total lipids (TL) accounted for approximately $20 \%$ of the mesocarp. Further analysis showed that the neutral lipid (NL) fraction accounted for at least $95 \%$ of the TL, and almost $90 \%$ of NL was triacylglycerol. Monoenoic acids accounted for at least $65 \%$ of the total fatty acids, and oleic acid, which is regarded as an especially important functional component of avacado accounted for approximately $50 \%$ of the monounsaturated fatty acids. A comparison of the Japanese avocado cultivars and an imported avocado cultivar in the present study revealed no significant differences in the lipid and fatty acid compositions. Therefore, production of avocado fruit, which is rich in various nutritional components, is expected to be increased on a larger number of farms in Japan in the future. It is believed to be necessary to carry out further verification, such as the establishment of a cultivation technique adoptable to Japan, examination of optimal soil and land features, and cultivar selection.
\end{abstract}

Key words: avocado, fatty acid, oleic acid, agricultural product, Japan

\section{INTRODUCTION}

Most of the commercially available avocado fruits, which have recently been gaining popularity in Japan, are imported. The current biggest exporter of the avocado fruits available in Japan is Mexico, and the total amount of imports is nearly 30,000 tons. The latitudinal range for tropical avocado fruit is from $40^{\circ} \mathrm{S}$ to $40^{\circ} \mathrm{N}$ because of the temperature profile; however, a cold-hardy cultivar can grow at a much lower temperatures. In Japan, which is located at the northern limit of the range for the growth of avocado fruit, the cold-hardy avocado cultivars, Fuerte cultivar and Bacon cultivar, have been grown and harvested on a small scale in warm areas (around $35^{\circ} \mathrm{N}$ ) on the Izu Peninsula and in Wakayama Prefecture. The Plant Protection Law requires imported avocado fruits to be treated at high temperature. Although they need to be ripened after the harvest, avocado fruits are generally harvested in a very unripened condition prior to export to Japan. In addi- tion, the quality is often deteriorated by cold storage in the domestic distribution system. As avocado fruit, which is also referred to as "butter fruit", has been eaten in various places, it has gained recognition for its high nutritional value. In particular, the content of lipids in avocado fruit is significantly higher than in other fruits, avocado fruit is used as a high-energy food source. Moreover, avocado oil is one of kinds of oil used all over the world and has been used both as a food and as constituent in cosmetics. The consumption of such highly nutritious avocado fruit in Japan is assumed continue to expanded due to the high level of health consciousness among Japanese; therefore, efforts will be made to provide safe, delicious, domestically produced avocado fruit. It is predicted that the average temperature in Japan will rise due to changes in the global environment, such as the progress of global warming, and the number of areas in Japan where avocado fruit can grow will also increase. There are many reports on the lipids

*Correspondence to: Fumio Takenaga, Department of Food Science and Technology, College of Bioresource Sciences, Nihon University, 1866, Kameino, Fijisawa-shi, Kanagawa, 252-8510, JAPAN

E-mail: takenaga@brs.nihon-u.ac.jp

Accepted June 26, 2008 (received for review April 18, 2008)

Journal of Oleo Science ISSN 1345-8957 print / ISSN 1347-3352 online

http://www.jstage.jst.go.jp/browse/jos/ 
contained in avocado fruit ${ }^{1-6)}$; however, there has been no study on nutrient components including lipids which are contained at a significantly higher level than in other fruits harvested in Japan. Hence, the lipid and fatty acid compositions in the mesocarp and seed of domestic avocado fruit were analyzed in order to examine the possibility of avocado fruit becoming an agriculture product grown in Japan in the future. The results of the experiments will be described in this report. The same experiments were conducted on commercially available imported avocado fruit, and the results were compared with those of the domestic avocado fruit.

\section{EXPERIMENTAL}

\subsection{Plant material}

Experiments were carried out with two avocado cultivars, the Fuerte cultivar and the Bacon cultivar, which were domestically grown in Numazu City, Shizuoka Prefecture. An imported avocado, the Hass cultivar, which was purchased from a supermarket in Tokyo, was subjected to the same experiments for comparison. Samples of these three cultivars were obtained at the fully ripened stage, and the seed and mesocarp were immediately separated. The separated seed and mesocarp were cut into pieces of an appropriate size and subjected to the experimental procedures. Five samples for each cultivar were used to obtain a mean value for each cultivar.

\subsection{Isolation of total lipids}

Total lipids (TL) were extracted and purified from each avocado fruit according to the method by Folch et al. using chloroform/methanol $(2: 1, \mathrm{v} / \mathrm{v})^{7}$. The obtained total lipids were fractionated into neutral lipids (NL), glycolipids (GL), and phospholipids (PL) by silicic acid column chromatography ${ }^{8)}$. The lipid fractions were identified and quantified by thin-layer chromatography using $\mathrm{Rf}$ values of standard lipids. Solvent systems were n-hexane:diethylether:acetic acid $(80: 20: 1, \mathrm{v} / \mathrm{v})$ for NL, chroloform:methanol $(95: 12, \mathrm{v} / \mathrm{v})$ for GL, and chroloform:methanol:water (65:25:4,v/v) for PL.

\subsection{Analysis of fatty acid composition}

Fatty acid methyl esters were prepared by transesterification with $15 \%-\mathrm{BF}_{3}$ in methanol. Fatty acid composition was analyzed by detection on a 5890 seriesII GC (Agilent Technologies, Inc., Santa Clarita, CA, U.S.A.) equipped with an FFS capillary column (ULBON-HR-SS-10; $0.25 \mathrm{~mm}$ I.D. $\times 50 \mathrm{~m}$, Shinwa Chemical Industries, Inc., Tokyo, Japan) was used. The FID and injector port were maintained at $250^{\circ} \mathrm{C}$. Column temperature was programmed to ramp from $150^{\circ} \mathrm{C}$ to $210^{\circ} \mathrm{C}$ at $2^{\circ} \mathrm{C}$ per minute. The flow rate of helium carrier gas was $0.8 \mathrm{ml} / \mathrm{min}$. Fatty acid methyl esters were identified by comparing retention times between the fatty acid methyl esters and the respective fatty acid methyl ester standards.

\section{RESULTS AND DISCUSSION}

\subsection{Contents and chemical properties of total lipids}

The TL content and chemical properties of the mesocarp and seed of each cultivar are shown in Table 1. TL content in the mesocarp of domestic cultivars was $18.7 \pm 0.61 \%$ $(n=5$, average) and $21.8 \pm 0.62 \%$ for the Fuerte cultivar and the Bacon cultivar, respectively, while that of the imported Hass cultivar was $18.2 \pm 0.53 \%$. As the highest mesocarp TL content was observed in the Bacon cultivar, it is assumed that differences in TL content are attributable to the differences among cultivars. The variation in TL content among the 5 samples of each of the cultivars was not great. The TL content has been reported to increase to $20 \%$ or higher after ripening ${ }^{5}$, and the same trend was also observed in the present study for the cultivars grown and harvested in Japan. The TL content in seed was 1.1\%, $1.6 \%$, and $1.1 \%$ in the Fuerte, Bacon, and Hass cultivars, respectively. TL content was much lower in the seed than in the mesocarp for all the cultivars. The chemical properties (Table 1) of the TL fraction differed between the mesocarp and seed; however, no significant difference in this

Table 1 Chemical Properties of Total Lipids (TL) in Mesocarp and Seed of Avocado Fruits Harvested in Japan.

\begin{tabular}{|c|c|c|c|c|c|c|}
\hline & \multicolumn{3}{|c|}{ mesocarp } & \multicolumn{3}{|c|}{ seed } \\
\hline & Fuerte & Bacon & Hass $* 1$ & Fuerte & Bacon & Hass $^{* 1}$ \\
\hline TL content $(w t \%)$ & $18.7 \pm 0.61 * 2$ & $21.8 \pm 0.62$ & $18.2 \pm 0.53$ & $1.1 \pm 0.16$ & $1.6 \pm 0.16$ & $1.1 \pm 0.15$ \\
\hline Appearance $\left(25^{\circ} \mathrm{C}\right)$ & \multicolumn{3}{|c|}{ Yellowish green liquid } & \multicolumn{3}{|c|}{ Yellowish brown liquid } \\
\hline Acid value & 2.3 & 1.7 & 1.5 & 6.9 & 9.5 & 5.4 \\
\hline Iodine value & 92.4 & 92.8 & 94.3 & 120.9 & 114.6 & 118.4 \\
\hline Saponification value & 194.2 & 193.8 & 195.1 & 204.2 & 204.1 & 203.0 \\
\hline
\end{tabular}

* 1: exported from USA (California)

$* 2$ : average date $(\mathrm{n}=5) \pm \mathrm{SD}$ 
experiment was observed among the domestic cultivars and the imported cultivar.

\subsection{Lipid composition}

The composition of TL is expressed as a percentage of NL, GL, and PL in Table 2. The percentages of NL in TL were $95 \%$ to $97 \%$ and $77 \%$ to $80 \%$ in mesocarp and seed, respectively. While a difference in NL content between the mesocarp and seed was observed, there was no significant difference among the cultivars. GL accounted for around $3 \%$ of TL in the mesocarp and $12 \%$ to $13 \%$ in the seed, and PL accounted for $1 \%$ to $2 \%$ and $8 \%$ to $11 \%$, respectively. Thus, as for the NL content, a difference in distribution between mesocarp and seed was also observed for GL and PL.

\subsection{Lipid composition of NL, GL and PL}

The lipid composition of NL is shown in Fig. 1. The content of triacylglycerol, which was found to be highest among all the classes in both mesocarp and seed, was $87 \%$ to $89 \%$ (equivalent to at least $80 \%$ of TL) in mesocarp, and $70 \%$ to $73 \%$ (equivalent to approximately $55 \%$ of $\mathrm{TL}$ ) in seed. A difference was observed between these parts, but no significant difference was observed among the cultivars. In addition to triacylglycerol, other lipids, such as diacylglycerol, free fatty acids, and free sterol, were contained in both the mesocarp and seed, and the contents of these lipids in seed were higher than those in mesocarp.

The lipid composition of GL is shown in Table 3. The content of monogalactosyl-diacylglycerol was found to be highest in both parts, and it was approximately $40 \%$ in mesocarp and approximately $57 \%$ in seed, respectively. In addition to monogalactosyl-diacylglycerol, other lipids, such as acylsterylglucoside, sterylglucoside, cerebroside, and digalactosyl-diacylglycerol, were also observed. No significant difference was observed among the cultivars.

The lipid composition of PL is shown in Table 4. The contents of phosphatidylethanolamine (39\% to $42 \%$ in mesocarp and $30 \%$ to $32 \%$ in seed) and phosphatidylcholine (35\% to $37 \%$ and $29 \%$ to $32 \%$, as well) were high in both parts in all cultivars. Although there was a difference in the content of these lipids between the parts, these two lipids together accounted for approximately $70 \%$ in PL. In addition to these lipids, other lipids, such as phosphatidic acid, phosphatidylglycerol, and phosphatidylinositol, were detected. While there was a difference in the contents of these lipids between the parts, no significant difference was observed among the cultivars.

\subsection{Fatty acid compositon of TL}

The fatty acid composition of TL is shown in Table 5. The content of oleic acid (18:1n9) was highest in mesocarp in all three cultivars. While the content was $58 \%$ and $54 \%$ in the domestic cultivars Bacon and Fuerte, respectively,

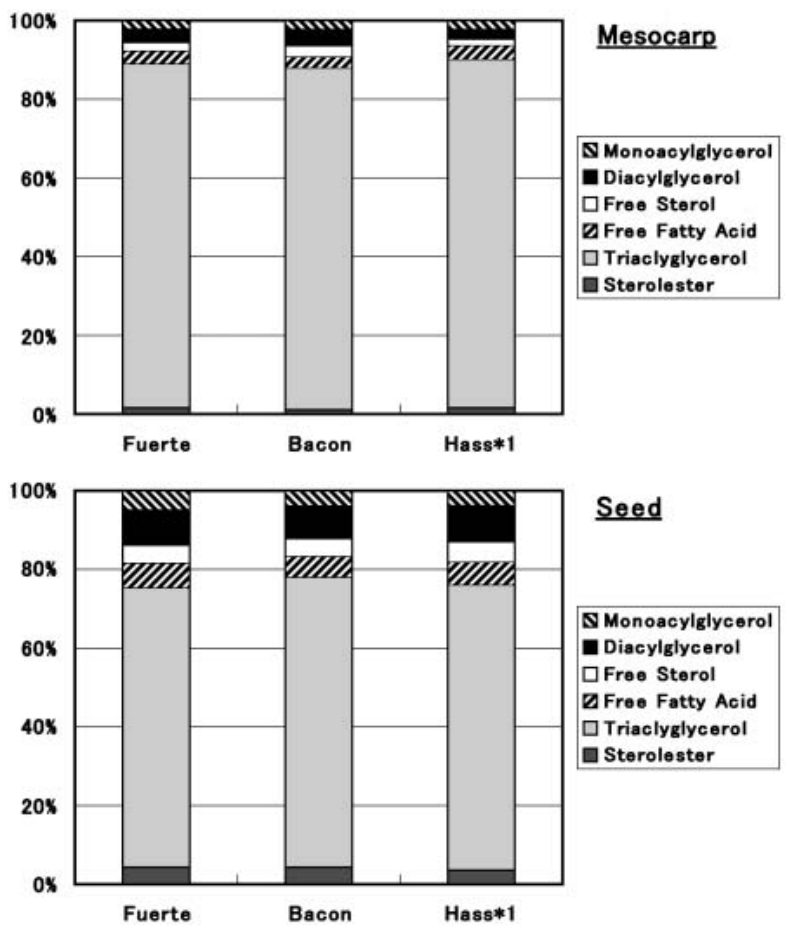

Fig. 1 Lipid Composition (wt\%) of Neutral Lipids (NL) in Mesocarp and Seed of Avocado Fruits Harvested in Japan.

Table 2 Lipid Composition (wt\%) of TL in Mesocarp and Seed of Avocado Fruits Harvested in Japan.

\begin{tabular}{|c|c|c|c|c|c|c|}
\hline & \multicolumn{3}{|c|}{ mesocarp } & \multicolumn{3}{|c|}{ seed } \\
\hline & Fuerte & Bacon & Hass $* 1$ & Fuerte & Bacon & Hass $* 1$ \\
\hline Neutral lipid fraction (NL) & 95.2 & 95.2 & 96.8 & 77.1 & 77.7 & 80.3 \\
\hline Glycolipid fraction (GL) & 3.2 & 2.7 & 2.5 & 12.0 & 13.2 & 12.3 \\
\hline Phospholipid fraction (PL) & 1.6 & 2.1 & 0.7 & 10.9 & 9.1 & 7.4 \\
\hline
\end{tabular}

$* 1$ : exported from USA (California)

$*$ average date $(\mathrm{n}=5)$ 
Table 3 Lipid Composition (wt\%) of Glycolipids (GL) in Mesocarp and Seed of Avocado Fruits Harvested in Japan.

\begin{tabular}{lcccccccc}
\hline & \multicolumn{3}{c}{ mesocarp } & & \multicolumn{3}{c}{ seed } \\
\cline { 2 - 3 } \cline { 7 - 8 } & Fuerte & Bacon & Hass*1 & & Fuerte & & Bacon & Hass*1 \\
\hline Acylsterylglucoside & 31.4 & 30.4 & 30.5 & & 18.6 & 18.0 & 17.5 \\
Monogalactosyl-diacylglycerol & 39.2 & 42.0 & 40.0 & & 56.3 & 57.5 & 57.7 \\
Sterylglucoside & 14.2 & 13.3 & 13.4 & & 10.5 & 10.1 & 10.8 \\
Cerebroside & 11.0 & 10.7 & 12.4 & & 10.5 & 10.7 & 9.8 \\
Digalactosyl-diacylglycerol & 2.7 & 2.0 & 2.5 & & 1.7 & 1.8 & 2.0 \\
Others & 1.5 & 1.6 & 1.2 & & 2.4 & 1.9 & 2.2 \\
\hline
\end{tabular}

$* 1$ : exported from USA (California)

$*$ average date $(\mathrm{n}=5)$

Table 4 Lipid Composition (wt\%) of Phospholipids (PL) in Mesocarp and Seed of Avocado Fruits Harvested in Japan.

\begin{tabular}{|c|c|c|c|c|c|c|}
\hline & \multicolumn{3}{|c|}{ mesocarp } & \multicolumn{3}{|c|}{ seed } \\
\hline & Fuerte & Bacon & Hass $* 1$ & Fuerte & Bacon & Hass*1 \\
\hline Phosphatidic acid & 10.4 & 9.3 & 11.4 & 17.6 & 15.4 & 14.5 \\
\hline Phosphatidylethanolamine & 39.5 & 41.7 & 38.6 & 31.9 & 30.7 & 31.3 \\
\hline Phosphatidylglycerol & 7.6 & 6.8 & 7.0 & 10.5 & 13.4 & 12.6 \\
\hline Phosphatidylcholine & 35.9 & 36.9 & 34.8 & 28.9 & 30.1 & 31.7 \\
\hline Phosphatidylinositol & 1.0 & 0.8 & 1.1 & 4.2 & 4.0 & 3.6 \\
\hline Others & 5.6 & 4.5 & 7.1 & 6.9 & 6.4 & 6.3 \\
\hline
\end{tabular}

* 1: exported from USA (California)

$*$ average date $(\mathrm{n}=5)$

that was only $46 \%$ in the imported Hass cultivar. Such a difference in content is assumed to be due to the difference in cultivar; however, it may also be due to domestic cultivation or damage caused during the process of importing. Further investigation needs to be conducted on this point. Different from other fruits, avocado fruit contains a large amount of fat in the mesocarp and, moreover, it can be eaten readily; therefore, it is expected to be a good source of oleic acid. In addition, the content of linoleic acid was as low as approximately $11 \%$, and the content of monoenoic acids, including oleic acid, was at least $65 \%$. It was also found that, although there was less than $10 \%$, the content of monoenoic acids (16:1n7 and 18:1n7) was high in the imported Hass cultivar. It should be noted that the results of the present study, such as observation of the high oleic acid ratio agreed with previous reports.

The content of linoleic acid was $35 \%$ to $38 \%$ in seed, which was the highest, followed by $18: \ln 9$ (22\% to $24 \%$ ) and 16:0 (17\% to 19\%). The content of $\alpha$-linolenic acid was found to be $4 \%$ to $5 \%$. According to these observations, it was found that the fatty acid composition in seed was largely different from that in mesocarp. Due to such a difference, the content of total monoenoic acids was at least $65 \%$ in mesocarp while it was $29 \%$ to $34 \%$ in seed, and the content of total polyenoic acids was approximately $12 \%$ in mesocarp while it was at least $40 \%$ in seed, a significant difference was observed between the parts.

\subsection{Fatty acid composition of NL, GL and PL}

The differences in the fatty acid composition of main fatty acids among NL, GL, and PL are shown in Fig. 2.

In NL of mesocarp, main fatty acids were 18:1n9, 16:0 and 18:2n6, and the content of 18:1n9 in the imported Hass cultivar was low similarly in the case of TL. In NL of the seed, main fatty acids were 18:2n6, 18:1n9, 16:0 and 18:3n3. As compared to the contents of main fatty acids in TL, some differences (a lower content of 18:2n6 and a higher content of 16:0 of NL) were obtained. Although the proportions in NL were similar to those in TL in mesocarp, a difference between TL and NL was obtained in seed. Such a difference is assumed to be due to the difference in NL content in TL. 
Table 5 Fatty Acid Composition (area\% in GC) of TL in Mesocarp and Seed of Avocado Fruits Harvested in Japan.

\begin{tabular}{|c|c|c|c|c|c|c|}
\hline & \multicolumn{3}{|c|}{ mesocarp } & \multicolumn{3}{|c|}{ seed } \\
\hline & Fuerte & Bacon & Hass $* 1$ & Fuerte & Bacon & Hass $* 1$ \\
\hline $12: 0$ & $\operatorname{tr}^{* 2}$ & $\operatorname{tr}$ & $\operatorname{tr}$ & 0.6 & 0.2 & 0.3 \\
\hline $14: 0$ & 0.1 & $\operatorname{tr}$ & 0.1 & 1.0 & 1.3 & 0.9 \\
\hline $16: 0$ & 19.9 & 18.6 & 20.0 & 17.8 & 17.7 & 19.0 \\
\hline $16: \ln 7$ & 5.7 & 4.9 & 9.2 & 4.6 & 4.4 & 2.4 \\
\hline $17: 0$ & $\operatorname{tr}$ & $\operatorname{tr}$ & $\operatorname{tr}$ & 0.3 & 1.1 & 0.5 \\
\hline 18:0 & 0.7 & 0.8 & 0.4 & 0.9 & 1.1 & 1.5 \\
\hline $18: \ln 9$ & 54.4 & 58.2 & 45.9 & 24.0 & 24.1 & 22.4 \\
\hline $18: \ln 7$ & 5.3 & 4.9 & 9.7 & 3.6 & 2.8 & 2.7 \\
\hline $18.2 \mathrm{n} 6$ & 11.6 & 10.7 & 12.5 & 35.3 & 36.1 & 38.2 \\
\hline $18: 3 n 3$ & 0.8 & 0.8 & 1.1 & 5.3 & 4.1 & 5.4 \\
\hline 20:0 & 0.1 & 0.1 & $\operatorname{tr}$ & 0.7 & 0.8 & 0.3 \\
\hline $20: \ln 9$ & 0.4 & 0.5 & 0.4 & 2.0 & 2.0 & 1.8 \\
\hline $22: 0$ & $\operatorname{tr}$ & $\operatorname{tr}$ & $\operatorname{tr}$ & 0.4 & 0.7 & 0.5 \\
\hline $24: 0$ & $\operatorname{tr}$ & $\operatorname{tr}$ & $\operatorname{tr}$ & 0.4 & 0.7 & 0.8 \\
\hline Others & 1.0 & 0.5 & 0.7 & 3.1 & 2.9 & 3.3 \\
\hline Saturated acid & 20.8 & 19.5 & 20.5 & 22.1 & 23.6 & 23.8 \\
\hline Monoenoic acid & 65.8 & 68.5 & 65.2 & 34.2 & 33.3 & 29.3 \\
\hline Polyenoic acid & 12.4 & 11.5 & 13.6 & 40.6 & 40.2 & 43.6 \\
\hline
\end{tabular}

* 1: exported from USA (California)

*2: trace

In GL in mesocarp and seed, although main fatty acids were similar to those in TL, the contents of main fatty acids differed from each other; a higher content of 18:2n6 and a lower content of 18:1n9 in mesocarp, a lower content of 18:2n6 and a higher content of 16:0 in seed.

In PL of mesocarp, although main fatty acids were similar to those in TL, while the content of 18:3n 3 was at least $10 \%$ and the content $18: 2 \mathrm{n} 6$ was high, the contents of 18:1n9 and 16:0 were low. However, since the percentage of PL in TL was low, such properties of PL only slightly affected the fatty acid composition of TL. In PL of seed, the content of $18: \ln 9$ was approximately $45 \%$ for PL, and was largely different from that in TL, NL, and GL. This result was similar to the report by Pacetti et al. (2007).

\section{CONCLUSIONS}

The present study examined the lipid and fatty acid compositions of the total lipids of the avocado fruit grown and harvested in Japan located at the northern growth limit of avocado fruit. This study investigated the nutritional value of the avocado fruit, and further, compared the domestic avocado fruit cultivars with an imported commercially available avocado fruit cultivar. The results obtained in the present study showed no significant difference between the domestic cultivars and the imported cultivars in terms of the chemical properties and the composition of the lipids. However, further investigation should be conducted with more cultivars and in other components. It has been said that there is a difference in taste and also food safety between domestic and imported avocado fruits; thus, it is desirable to increase the amount of domestically produced avocados in the market. If global warming progresses in a way that causes a rise in the average temperature in Japan, avocado fruit may become an agricultural product with the possibility of becoming one of the products in Japan in the future. Hence, it is believed to be necessary to carry out further investigation on avocado fruit, which has a high nutritional value and can be readily eaten, so as to establish a cultivation technique adoptable to Japan through the examination of optimal soil and land features and cultivar selection.

\section{References}

1. Mazliak, P. Avocado lipids I. Fatty acid composition of different regions of the fruit, Fruits 20, 49-57 (1965).

2. Mazliak, P. Avocado lipid constituents, Fruits 26, 615623 (1971).

3. Tango, M.; Da Costa, S.I.; Antunes, A.J.; Figueriedo, 

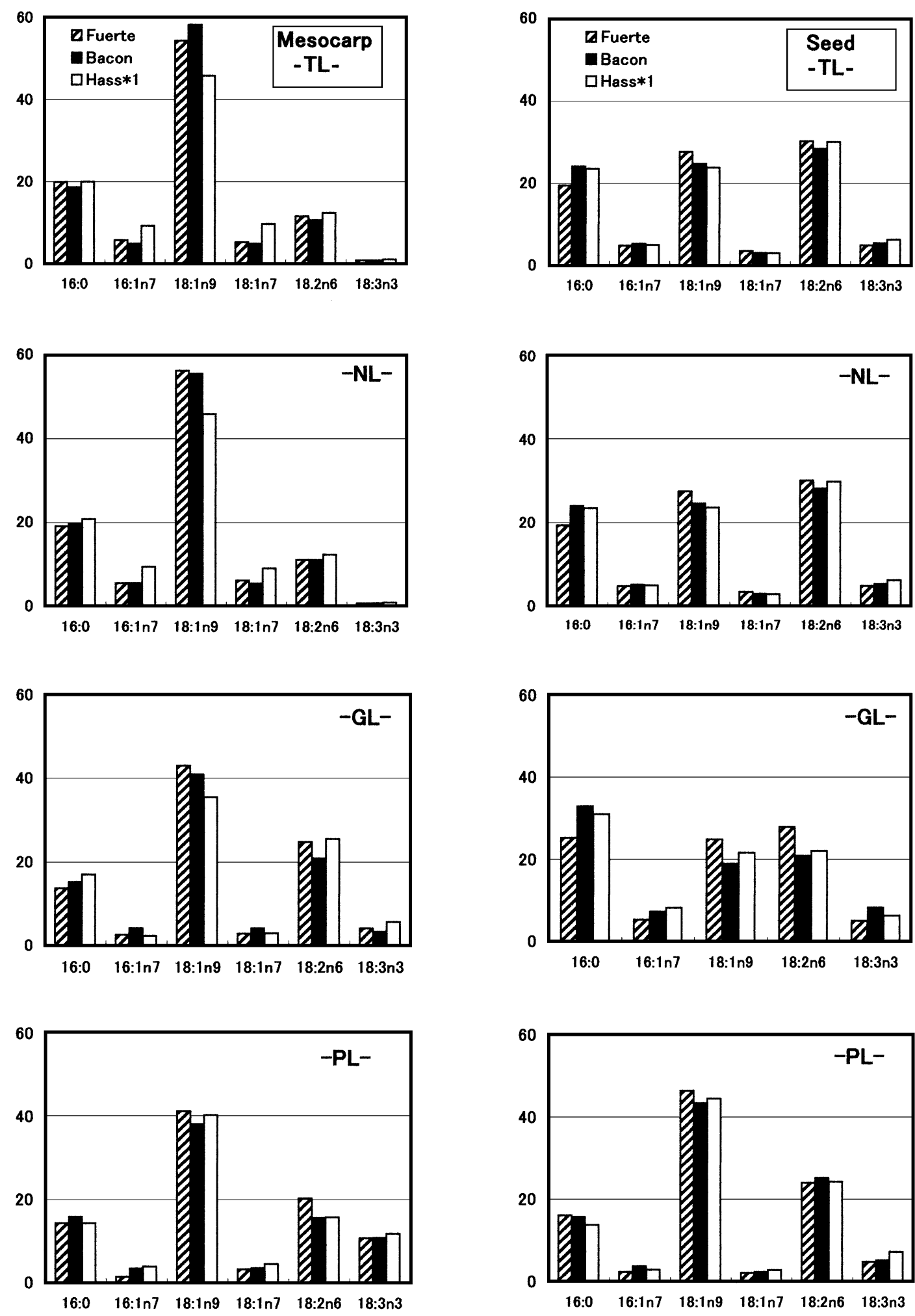

Mesocarp

Seed

Fig. 2 Comparison of Main Fatty Acid Composition (\%) of TL, NL, GL and PL in Mesocarp and Seed of Avocado Fruits Harvested in Japan. 
I.B. Composition of fruit oil of different varieties of avocado grown in San Paulo. Fruits 27, 143-146 (1972).

4. Gaydou, E.M.; Lozano, Y.; Ratovohery, J. Triglyceride and fatty acid compositions in the mesocarp of Persea Americana during fruit development. Phytochem. 26, 1595-1597 (1987).

5. Ozdemir, F.; Topuz, A. Changes in dry matter, oil content and fatty acids composition of avocado during harvesting time and post-harvesting ripening period. Food Chem. 86, 79-83 (2004).

6. Pacetti, A.; Boselli, E.; Lucci, P.; Frega, N.G. Simultaneous analysis of glycolipids and phospholipids molecular species in avocado (Persea americana Mill) fruit. $J$. Chromatography A 1150, 241-251 (2007).

7. Folch, J.; Lees, M.; Slone-Stanlet, G.H. A simple method for the isolation and purification of total lipids from animal tissues. J. Biol. Chem. 226, 497-509 (1957).

8. Rouser, G.; Kritchevsky, G.; Simon, G.; Nelson, G.J. Quantitative analysis of brain and spinach leaf lipids employing silicic acid column chromatography and acetone for elution of glycolipids. Lipids 2, 37-40 (1967).

9. Berry, E.M.; Eisenberg, S.; Haratz, D.; Friedlander, Y.; Norman, Y.; Kaufmann, N.A.; Stein, Y. Effects of diets rich in monounsaturated fatty acids on plasma lipioproteins-The Jerusalem nutrition study: hogh MUFAs vs high PUFAs, Am. J. Clin. Nutr. 53, 899-907 (1991).

10. Mate, P.; Alonso, R.; Lopez-Farre, A.;Ordovas, J.M.; Lahoz, C.; Garces, C.; Caramelo, C.; Codoceo, R.; Blazquez, E.; Oya, M. Effect of dietary fat saturation on LDL oxidation and monocyte adhesion to human endothelial cells in vitro. Arterioscler. Thromb. Vasc. Biol. 16, 1347-1355 (1996). 